TRADUÇÃO 



\section{A tradução como prática filológica poemata lusitane scripta ad Latinum translata}

Johnny José Mafra

PUC Minas

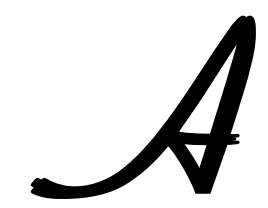

o ensejo das homenagens prestadas pela Faculdade de Letras da UFMG à professora Angela Vaz Leão em comemoração do seu aniversário, pareceu-me oportuno, como preito de amizade, apresentar este exercício de escrita em latim de uma seleção de poemas de autores portugueses e brasileiros, entendendo que, por si só, esse trabalho representa uma incursão na prática filológica que constitui não apenas a especialidade da professora, mas o objeto central a que ela vem devotando o melhor de seus esforços na vida universitária.

Ao prazer proporcionado pelo sentido lúdico da tradução ajunto o proveito que tal exercício traz para a manutenção do latim, uma vez que ativa os cuidados necessários à correta expressão da sintaxe que tem na morfologia do caso o recurso criador da relação sintagmática e do sentido da frase.

Para amparo da minha proposta trago a experiência de Joaquim Mattoso Câmara Júnior que, numa discussão sobre filologia e linguística e falando da "necessidade de compreender textos antigos cuja língua é obsoleta", propõe um novo tipo de comparação, "a da linguagem do passado com a do presente". Isto se torna imperativo quando os textos antigos são do domínio da literatura, caso em que se impõe "compreender os 
traços linguísticos obsoletos a fim de captar a mensagem artística". Diz o autor que a esse tipo de estudo tem-se chamado filologia desde os antigos gregos. ${ }^{1}$

Aqui proponho atividade inversa, que é escrever na língua do passado um texto escrito na língua do presente. É também uma atividade inversa do consenso de que "a língua-alvo deve ser exclusivamnte a língua materna" ${ }^{2}$ A operação exige o conhecimento de formas passadas, que Câmara Jr. chama de obsoletas, não usuais no presente, porque não seria às vezes suficiente conhecer a forma latina etimologicamente semelhante à portuguesa, pois o esvaziamento de sentido torna a nova configuração estranha à palavra antiga. Essa prática é a chamada retroversão ou versão usual nos exercícios pedagógicos, como estratégia do ensino das línguas estrangeiras, neste caso, especialmente, a língua latina. Formas obsoletas a que se refere Câmara Jr. são também as modalidades sintáticas antigas não mais usuais na língua atual, modalidades rítmicas, a métrica e os recursos estilísticos que o tradutor deverá conhecer para a expressão apropriada.

Ao me dispor a este trabalho sobre tradução, não me furto à tentação de retornar aos momentos mais antigos da cultura greco-latina para entender e justificar como e por que ainda hoje subsistem tantas dúvidas quanto à validade da tradução, sobretudo, de textos literários.

A mais antiga polêmica sobre tradução de texto literário na Europa é a que envolve os poetas latinos Plauto e Terêncio, século III a.C., acusados por críticos contemporâneos de deturpar ou manchar os originais da comédia grega com a prática chamada então contaminatio 'contaminação'. Acusava-se

${ }^{1}$ CÂMARA JR., 1986, p. 10.

${ }^{2}$ LADMIRAL, 1979, p. 16. 
a esses poetas de misturar partes de diferentes comédias gregas em uma única latina. Esse seria um jeito latino de apropriação da literatura grega, entendendo-se a imitatio como adaptação ao ambiente em que seria representada a peça.

Anterior a Plauto e Terêncio, foi Lívio Andronico, escravo tarentino introduzido em Roma, o primeiro a representar em latim a comédia grega, nos Ludi Romani (Jogos Romanos) de 240 a.C., comemorativos da vitória sobre Cartago. Não se conhece o teor de suas adaptações, pois os originais gregos se perderam e dessas comédias só restam escassos fragmentos. Sabe-se, no entanto, por informação de autores da época, da existência do poeta tarentino e de sua atuação como pioneiro na produção de uma literatura culta em Roma, o que lhe dá o honroso título de introdutor do teatro grego em Roma e fundador da literatura latina.

Sabe-se também que Andronico, que ensinava aos "filhos de família", traduziu para o latim a Odisseia, no antigo verso itálico chamado saturnino, adaptando o que lhe pareceu capaz de facilitar ao estudante latino a leitura da epopeia homérica. Assim, no primeiro verso da sua Odisseia já a parece a opção pelos mitos itálicos. Em vez da invocação $M u s a$ da abertura do poema homérico (Andra moi énnepe, Mousa, polítropon) Andronico consagra as deusas Camenas ${ }^{3}$ como inspiradoras do seu canto.

Virum mihi, Camena, insece versutum

Conta-me, Camena, o herói astuto

Noutro verso, a invocação Pater noster, Saturni filie... (ó filho de Saturno, nosso pai...) confirma a adaptação da Odisseia grega à cultura itálica, pois o poeta substitui o deus grego Cronos por

${ }^{3}$ As Camenas eram antigas divindades da Itália que os poetas confundiram com as Musas gregas. Eram conhecidas por dois nomes: Juturna e Carmenta. (Spalding, Tassilo O. Dicionário da mitologia latina. São Paulo: Cultrix/MEC, 1972). 
Saturno, deus itálico da agricultura, ${ }^{4}$ e, em vez de Hermes e Hera, usa Mercúrio e Latona, como neste fragmento

Mercurius cumque eo filius Latonas

...e com ele, Mercúrio, filho de Latona.

Uma conclusão preliminar pode-se aventurar: já existiria, naqueles tempos, a preocupação com a transposição de um texto de uma língua para outra língua, de modo a fazer que o leitor entendesse na sua língua e na sua cultura o que foi escrito em outra língua para leitores de outra cultura.

Se não há documentos bastantes para avaliar a experiência de Andronico, há, no caso de Plauto e Terêncio, pois, embora ainda de forma obscura, encontram-se nos textos dos próprios poetas informações que permitem acompanhar a polêmica e avaliar como se dava a apropriação de obras estrangeiras. Uma dificuldade, porém, se põe ao pesquisador moderno: não existem os originais gregos, que lamentavelmente se perderam, e, dessas fontes, algumas só são conhecidas pelos títulos.

O que se costuma afirmar é que a comédia latina não é uma simples tradução da comédia ateniense, embora não se possa saber o que significaria, naquela época, 'tradução'. Mas pode-se ter como certo que o verbo traducere não era usado para expressar o que aqui chamamos de tradução. No prólogo de Asinaria (v.11) e de Trinummus (v.19), Plauto emprega o verbo vertere ou vortere

\section{Maccus vortit barbare}

Maco verteu em língua bárbara

e em Casina (v.31-4) diz apenas graece scribere e latine scribere

${ }^{4}$ Sobre a identificação de Saturno e Cronos, um mito mais recente narra que este, depois de ser expulso do céu por Júpiter, veio esconderse no Lácio, onde foi acolhido por Jano, rei lendário da Itália. 


\section{...Diphilus \\ hanc graece scripsit, postid rursum denuo \\ latine Plautus ...... \\ Dífilo escreveu em grego, e depois dele escreveu de novo em latim Plauto.....}

Vê-se então que, para indicar a passagem de uma língua para outra, usava-se o verbo vertere (ou vortere), seus compostos convertere, transvertere, e ainda os verbos imitari, explicare, interpretari, exprimere e reddere. Traducere encontra-se em Noctes atticae de Aulo Gélio, ${ }^{5}$ do século II d.C., na expressão vocabulum graecum traductum in linguam romanam (I,18,1), mas certamente para indicar o que já se lia em De Oratore de Cícero (III, 42, 167), com o sentido de empréstimo ou importação de um vocábulo de outra língua. Na verdade, traducere denota, para situações diferentes, transferir, passar de um lugar a outro, sentido que se encontra em tradux, -ucis, 'enxerto' ou 'broto' de videira que se passa de uma planta para outra. Mais tarde, na Idade Média, introduziu-se o verbo transferre, cujo particípio translatus derivou translatare, donde se formam translatio e translator. Mas o verbo traduzir, originado do latim traducere, só aparece no Humanismo, com Leonardo Bruni, numa carta de 5 de setembro de 1400 d.C., e remontaria à citada expressão encontrada em Noctes atticae. ${ }^{6}$

Quanto ao sentido de vortere, pouco esclarecem os comentários dos autores antigos que apenas repetem as expressões usadas pelos autores da comédia.

Cícero (séc.I $a$ C.), em De optimo genere oratorum (VI,18), diz que os trágicos e os cômicos "vertiam" as obras gregas: e Graecis conversis... versibus...; e, em De finibus (I,II,4), fala em reprodução literal: fabellas latinas ad verbum de Graecis expressas 'as comédias latinas reproduzidas das gregas palavra por palavra'. Aqui, parece, o autor refere-se à modalidade de tradução que chamamos

\footnotetext{
${ }^{5}$ AULE GELLE, I, 18, 1.

${ }^{6}$ FURLAN, 2003, p. 11.
} 
de literal, mas o mesmo Cícero, em Academicae (I,III,10), afirma que os trágicos e muitos outros (multi alii) reproduziam não as palavras, mas a força do sentido (non verba sed vim), com o que talvez quisesse dizer que eles adaptavam ou reinterpretavam as obras gregas. ${ }^{7}$

A esse respeito é, mais uma vez, significativo o testemunho de Plauto que, no prólogo de Menaechmi (Os Menecmos, ou a comédia de enganos) v.7-12, insinua, com tom jocoso ou de galhofa, como os poetas latinos se apropriavam dos temas gregos, 'simulando que a ação se passa em Atenas' ...omnis res gestas esse Athenis..., para ficar mais interessante. E, falando de si mesmo, diz que sua peça imita uma peça grega (graecissat), não "aticiza" (atticissat), mas "siciliciza" (sicilicissat), isto é, não da Ática mas da Sicília. Observe-se a propósito o tom jocoso dos verbos graecissat, atticissat, sicilicissat, que introduzem a ideia de "imitar" ou "fazer como".

Aulo Gélio (séc. II d.C.), em Noctes Atticae (II,XXIII), fala da inferioridade das comédias latinas e diz que elas são 'tomadas e vertidas das gregas' ...sumptas ac versas de Graecis. Mas não deixa claro o sentido de vertere. Mais adiante, porém, ao comentar a comédia Plocium, de Cecílio, faz um confronto com o original de Menandro, Plókion, e diz que nada há de comum entre as duas, a não ser as personagens, a situação e a ideia geral. Acrescenta que a comédia de Cecílio é uma análise sumária do original, que o autor procurou desenvolver à sua maneira. Isto significa que Cecílio se afastava do seu modelo ou modificava o texto grego.

Dando um salto, da antiguidade a estes dias, e abandonando as especulações dos especialistas sobre as modalidades de tradução, tomo como referência a bem sucedida experiência de Padre Pedro Sarneel e José Lourenço de Oliveira concretizada na tradução para o latim dos quarenta poemas de Henriqueta Lisboa, do livro Montanha viva - Caraça. Os dois tradutores são,

MAFRA, 201, p 46-48. 
o primeiro, professor do Caraça no início do século $\mathrm{XX}$, perito em poesia latina, falecido em 1963, o outro, um ex-aluno do Caraça, entre 1916 e 1922, fundador e professor de língua latina da Faculdade de Letras da UFMG, falecido em 1984.

Na sua introdução (p.18) diz o padre Sarneel que "traduzir é difícil" e que "compor é mais simples". E a seguir ele explica que, no ato da composição "as musas acorrem numerosas, todas inspiram". Assim, "sem compromisso, larga-se uma para acompanhar outra". 8

Sobre a tradução e o tradutor, o autor pontifica com sabedoria:

Quem traduz não pode voar para onde e por onde a imaginação o leva. Tem de pensar e escrever como o seu modelo pensou e escreveu. Deve retratar o mais exatamente possível a personalidade moral e literária do autor original, a profundeza e elevação dos seus conceitos e imagens, o colorido e a música do seu estilo. Mesmo uma tradução livre está presa à inspiração de outrem.

Diante da dificuldade da tradução decorrente da diversidade das línguas, o latim e o português, padre Sarneel se dizia desanimado e dava as razões. Se é difícil o simples passar de uma língua a outra, mais difícil se torna quando se trata de poesia. Há uma diferença profunda entre o verso português e o latino, seja metrificado, seja o verso livre. No verso latino o ritmo não se baseia na acentuação das palavras, como no português, mas na quantidade da sílaba, longa e breve, isto é, na duração com que a sílaba é pronunciada. Não se conhece no verso latino a rima do verso português, criadora de facilidades no versejar, e a ordenação dos segmentos poéticos, chamados metros ou pés, não é a mesma no português e no latim.

Para tornar possível a empreitada, muda-se a técnica: em vez dos hexâmetros da métrica latina, adota-se o ritmo acentual, isto

8 SARNEEL, 1977, p. 18. 
é, o verso formado de sílabas tônicas e átonas com que os poetas cristãos da Idade Média compunham seus hinos litúrgicos, tal como o hino eucarístico Tantum ergo escrito por Tomás de Aquino no século XIII, e que já se podia ler nos poemas buranos (Carmina burana) dos goliardos ou clérigos vagantes (clerici vagi) da Baviera. ${ }^{9}$ Essa opção, que o professor Lourenço chama de "infidelidade", levou os tradutores a "transigir" e usar, "em vez da métrica romana, a intensidade pós-românica do metro" ${ }^{10}$

É com apoio nesses preceitos que empreendi o exercício escolar de escrever em latim alguns poemas de poetas brasileiros e portugueses, contemporâneos, modernos ou de passado mais distante. Não o fiz e não o faço por ofício, mas com certo senso de curiosidade e divertimento aliado à exercitação da gramática latina entendida em toda a sua extensão, na sintaxe, na morfologia, na estilística e na composição dos versos.

As dificuldades surgem imediatas. E paro, pensando: como os latinos diriam isso? Latini quomodo dixerint? Não é fácil saber. Mas vale o exercício.

A primeira experiência deu-se com a especulação em torno do poema "Para sempre" de Carlos Drummond de Andrade. O título comunica, de imediato, um significado difícil de explicar, mas parece que podemos entendê-lo, quase intuitivo.

Ora, a palavra latina que traduz sempre é semper, um advérbio que indica a duração sem fim, não carente de regime como a palavra portuguesa que, acumulando a ideia de tempo

${ }^{9}$ Os cantos goliárdicos são de autoria de estudantes pobres e clérigos dos anos 1000 a 1200 d.C., que ganhavam sustento cantando pelos mosteiros e palácios dos senhores feudais, conhecidos como "clérigos vagantes" ou "goliardos". A poesia tinha um caráter mundano, quase sempre erótico, era irreverente e provocadora da hierarquia eclesiástica. Esses clérigos irreverentes eram chamados de Golias, donde goliardos. (Woensel, 1994, p. 17).

${ }^{10}$ OLIVEIRA, 1977, p. 21. 
com a de espaço, permite o movimento em direção a esse espaço, o sempre, com a preposição para. Em latim, a preposição ad cumpre esse papel, mas não forma sintagma com semper.

A solução é buscar a palavra aeternum, um nome neutro empregado por aeternitas, mas surge outra dúvida: seria o título ad aeternum ou in aeternum? Faz diferença? Parece que faz. In implica a ideia de interioridade e $a d$, a de aproximação. Então, usa-se in, se sempre é aonde se chega e onde se permanece; ad, se é o estado ou a situação que se busca sem nunca se alcançar, pois desapareceria a infinitude.

Mesmo sem ter formado convicção sobre o emprego de qual preposição, pareceu melhor dizer Ad aeternum, levando em conta, ainda, o sentido da preposição in na expressão tu es sacerdos in aeternum com que o rito canônico proclama a consagração à vida religiosa.

A segunda experiência foi a tradução do soneto Fermoso Tejo meu do poeta seiscentista português Francisco Rodrigues Lobo (1579-1621), de linguagem clara e simples feita de estruturas impressionantemente parecidas com as estruturas do latim, o que tornou o exercício prazeroso e relativamente fácil.

Digo relativamente, porque, logo no início, surgiu pequeno embaraço: o latim formosus expressa bem a graça que o poeta dá ao seu rio com o adjetivo fermoso modificado pelo efeito da metafonia do "o" na primeira sílaba? Seria esta a boa tradução: formose Tage meus?

Não me pareceu que o latim, dessa forma, mantivesse o mesmo encanto do Fermoso Tejo meu. Forma expressiva de vitalidade e sensualidade só a encontrei no adjetivo venustus, que, não só etimologicamente leva a Venus, mas semanticamente comunica o encanto produzido pela deusa. Venustus, então, que, em latim, se usa para expressar a beleza de pequenas paisagens e pequenos objetos que se guardam "do lado esquerdo do peito" compôs o título e a abertura do soneto, com o apoio 
rítmico do vocativo mi em vez de meus e a plasticidade fônica do vocativo em " $\mathrm{e}$ ": Mi venuste Tage... A primeira estrofe se recompôs na língua-mãe que passou a ser língua-fim:

Fermoso Tejo meu, quão diferente

Te vejo e vi, me vês agora e viste:

Turvo te vejo a ti, tu a mim triste,

Claro te vi eu já, tu a mim contente.

Mi venuste Tage, quam dispar te
Video vidique, vides me et vidisti;
Turbidum te video, vides me tristem,
Purum videbam te, tu me contentum.

O grande desafio que agora se põe é dizer em latim o poema Autopsicografia de Fernando Pessoa. Aí pareceu fora de dúvida trocar simplesmente fingidor por fictor, sem preocupação com o termo latino que significa escultor, criador, inventor, pensando apenas na extensão do sentido para dissimulado, dissimulador, que é, pode-se dizer, de uso comum na língua portuguesa. Na verdade, nos autores latinos não há registro de fictor com a conotação de dissimulado, e o agente dissimulator, com cinco sílabas, não daria ao verso a leveza que se sente no verso do poeta português. Tampouco simulator seria a solução, por não existir, em uso, essa forma, e ainda porque o verbo simulare quebraria a graça que fingir traz aos dois versos seguintes. Não sei se seria a melhor opção: ita vehementer simulat / ut simulat quod est dolor... A conclusão que pareceu mais adequada foi usar fingere com o sentido metafórico que veio a se tornar denotativo de simular. Mas não termina aí a dificuldade da primeira estrofe: chega a fingir, com o sentido de "ser até capaz de", poderia ser construído tanto com o acusativo do supino do verbo venire: venit fictum quanto com accidit mais infinitivo: accidit fingere, mas pareceu mais produtivo manter, com o verbo fingere, estrutura parecida com a portuguesa, com prejuízo da ideia de "ser até capaz de". De qualquer forma, uma das duas versões seria a mais adequada: 
Poeta est fictor.

Ita vehementer fingit, ut fingit quod est dolor dolor quem vere sentit

ou

Poeta est simulator.

Ita vehementer simulat, ut simulat quod est dolor dolor quem vere sentit

Na mesma linha da versão de Francisco Rodrigues Lobo, Fernando Pessoa e Carlos Drummond de Andrade, segue-se semelhante exercício com poemas de Cecília Meireles, Gérson Cunha e Oswaldo Soares da Cunha. De Cecília Meireles, traduzi o poema Retrato. São versos tão simples, tão fáceis, tão certos, que escrevê-los em latim foi só uma questão de tempo. Para o português "ter", o dativo de posse seguido do verbo esse manteve o ritmo e a sonoridade do verso português, em vez do vulgar ego non habebam...:

mi non erat hic vultus hodiernus.

Eu não tinha este rosto de hoje,

Do mesmo modo, o primeiro verso da segunda estrofe. Como dizer em latim "estas mãos sem força"? ...manus sine vi? sine robore...? A custo a memória trouxe o adjetivo raro imbellis que expressa aquela incapacidade de lutar que está em "mãos sem força", isto é, mãos que já não são mais hábeis para a guerra, que venceram tantas adversidades. E o verso que ficou assim:

mi non erant hae imbelles manus.

eu não tinha estas mãos sem força.

De Soares da Cunha e Gérson Cunha busquei alguns sonetos para os quais quase sempre consegui o decassílabo correspondente ao verso português e alguma rima feliz que aproxima o latim daquela métrica pós-clássica que se valia da rima e de um número certo de pés ou sílabas. Na carência de 
um vocabulário mais rico, alguns versos não lograram essa igualdade, o que não frustrou o labor da tradução.

Para terminar, segue-se pequena antologia formada dos seis poetas selecionados para tão despretencioso exercício, que é, ao mesmo tempo, o mote para o pretendido ensaio sobre tradução.

\section{Referências}

AULE GELLE. Noctes atticae. Texte établi et traduit par Maurice Mignon. Paris: Garnier, s.d.

BARBOSA, Heloísa Gonçalves. Procedimentos técnicos da tradução. Campinas: Pontes, 1990.

CÂMARA Jr., Joaquim Mattoso. História da linguística. 4.ed. Petrópolis: Vozes. 1986.

FURLAN, Mauri. Brevíssima história da tradução no Ocidente: I Os romanos. In: Cadernos de Tradução, $\mathrm{n}^{\circ}$ VIII. Florianópolis: PGET, p. 11-28, 2003.

LADMIRAL, J.-R. Traduzir: teoremas para a tradução. Tradução de Cascais Franco. Lisboa: Europa-América. 1979.

MAFRA, Johnny José. O legado da comédia latina. Belo Horizonte: Edição do Autor, 2011. p. 46-48; 96.

OLIVEIRA, José Lourenço. Dedicatória. In: Henriqueta Lisboa. Montanha viva - Caraça (Mons vivus seu Mons caracensis). Belo Horizonte: O Lutador, 1977. p. 21-22.

SARNEEL, Pedro (Padre). Dedicatória. In: Henriqueta Lisboa. Montanha viva - Caraça (Mons vivus seu Mons caracensis). Belo Horizonte: O Lutador, 1977. p. 18-20.

SPINA, Segismundo. Apresentação. In: Carmina burana : canções de Beuern. 2.ed. São Paulo: Ars Poética, 1994. p. 9-15.

SPINA, Segismundo. A poesia dos goliardos. In: A lírica trovadoresca. São Paulo: Editora da Universidade de São Paulo, 1996. p. 27-30.

WOENSEL, Maurice van. Introdução. In: - Carmina burana: canções de Beuern. 2.ed. São Paulo: Ars Poetica, 1994. p. 17-22. 


\section{ANTOLOGIA \\ Francisco Rodrigues Lobo}

\section{Fermoso Tejo meu}

Fermoso Tejo meu, quão diferente

Te vejo e vi, me vês agora e viste:

Turvo te vejo a ti, tu a mim triste,

Claro te vi eu já, tu a mim contente.

A ti foi-te trocando a grossa enchente

A quem teu largo campo não resiste;

A mim trocou-me a vista em que consiste

O meu viver contente ou descontente!

Já que somos no mal participantes,

Sejamo-lo no bem. Oh, quem me dera

Que fôramos em tudo semelhantes!

Mas lá virá a fresca primavera:

Tu tornarás a ser quem eras dantes,

Eu não sei se serei quem dantes era.

\section{Mi venuste Tage}

Mi venuste Tage, quam dispar te

Video vidique, vides me et vidisti;

Turbidum te video, vides me tristem,

Purum videbam te, tu me contentum.

Te lente mutat ingens inundatio

Cui arva tua lata non resistunt;

Mutavit meum visum in quo consistit

Me contente aut moleste vivere.

Quoniam sumus in damno participes,

Esto id in bono. O utinam fueramus

Inter nos in omnibus quoque similes!

Veniet tamen viride primum ver:

Tu eris rursus is qui eras antea, Ego nescio si sim quis antea eram. 


\section{Fernando Pessoa}

\section{Autopsicografia}

O poeta é um fingidor.

Finge tão completamente, que chega a fingir que é dor a dor que deveras sente.

E os que leem o que escreve, na dor lida sentem bem, não as duas que ele teve mas só a que eles não têm.

E assim nas calhas da roda gira, a entreter a razão, esse comboio de corda que se chama coração.

\section{Autopsychographia}

Poeta est fictor.

Ita vehementer fingit, ut fingit quod est dolor dolor quem vere sentit.

Illi qui legunt quod scribit lecto in dolore beneplacent, non in duobus quos habuit, sed in eo quem non habent.

Et tunc in ambitu rotae vertitur, ludendo mentem, hic apparatus ex chorda qui nominat sese cor. 


\section{Carlos Drummond de Andrade}

\section{Para Sempre}

Por que Deus permite

que as mães vão-se embora?

Mãe não tem limite, é tempo sem hora, luz que não apaga quando sopra o vento e chuva desaba, veludo escondido na pele enrugada, água pura, ar puro, puro pensamento. Morrer acontece com o que é breve e passa sem deixar vestígio.

Mãe, na sua graça, é eternidade.

Por que Deus se lembra - mistério profundo de tirá-la um dia?

Fosse eu Rei do Mundo, baixava uma lei:

Mãe não morre nunca, mãe ficará sempre junto de seu filho e ele, velho embora, será pequenino feito grão de milho.

\section{Ad Aeternum}

Cur Deus matres abire sinit?

Non est matri limes, mater tempus sine hora, lucerna non exstinguenda cum ventus flat et caeli rorant, velutum absconditum intra rugosam pellem, lympha pura, aether purus, pura mens. Mori datur brevi rei quae sine vestigio transit. Mater, lepore suo, est perennitas. Cur meminit Deus - reconditum arcanum eam tollere die illa? Si Rex Mundi essem, legem proscripserim: Mater nunquam morietur, mater semper manebit apud filium qui, senex tamen, parvulus erit sicut milium.

\section{Cecília Meireles}

\section{Retrato}

Eu não tinha este rosto de hoje, Assim calmo, assim triste, assim magro, Nem estes olhos tão vazios, Nem o lábio amargo. 
Eu não tinha estas mãos sem força,

Tão paradas e frias e mortas;

Eu não tinha este coração

Que nem se mostra.

Eu não dei por esta mudança, Tão simples, tão certa, tão fácil:

- Em que espelho ficou perdida a minha face?

\section{Simulacrum}

Mi non erat hic vultus hodiernus,

Modo lentus, modo tristis, modo macer,

Neque hi oculi tam inanes,

Neque labia amara.

Mi non erant hae imbelles manus,

Tam inertes et frigidae et mortuae;

Mi non erat hoc cor

Quod nec se monstrat.

Ego non percepi hunc mutatum,

Tam simplicem, tam notum, tam facilem:

-Quo in speculo sese perdidit mea facies?

\section{Gérson Cunha}

\section{Outono}

Ao visivo prenúncio deste outono,

Antevejo as manhãs de argentaria;

E se arvora de alguma primazia

A bem-vinda e fugente rima em "ono".

Valha o gozo do espírito - o tono,

Com que já me despeço da ardentia;

Valha o sol amarelo, em dilogia,

Sobre tua paisagem de abandono.

Estação abismal da quaresmeira, Tua brisa sutil, que o flóreo invade, É roxo farfalhar de ave rameira... 
Outono, pelos anos contrafiz-te!

E se lembras o irmão de soledade,

Espelha-te nest'alma êxul e triste!

\section{Autumnus}

Cum nuntiat se visibilis autumnus

Primam lucem praevideo argentinam;

Et sibi quoddam principatum arrogat

Bene gratus et perpaucus sonus unus.

Plus valeat gaudium spiritus - hic tonus,

Quocum dico vale aestui febrili;

Valeat flavus sol, deliramentum,

Super visum desertum, valeat onus.

Abysmale tempus quadragesimariae,

Aura tua subtilis, quae saltum implet,

Violaceum murmur est avis arboreae...

Autumne, te per annos simulavi!

Et si memoriam tenes solitarii fratris,

Vide te in hac mente exsule tristique.

\section{Dúbio céu}

Às vezes, no correr do dia-a-dia, Relembro, inspirado na velhice, A leveza que foi a meninice, Embarcada num folho de magia.

Nessa altura, entretanto, inda queria

Que minh'alma outra vez se colorisse,

Que o sorriso do espírito sorrisse, Apesar de afincada apostasia.

Na verdade, essa chama do Infinito, Muito embora se tenha por sagrada, Bem no fundo, inda pode ser um mito...

Mas se há flores nos baldos da palhada, (Aspira ardentemente este incontrito), Que o Destino também não seja o Nada! 


\section{Dubium caelum}

Saepe me, currente die, sene

Levitatem priscam puerilem

Memini in folio magico peregrinantem.

Sed interea adhuc volebam ut anima

Colorem rursus duceret risusque spiritus,

Fides quamvis pauca, rideret.

Vere, flama ista Immensitatis,

Sacra quamvis multi esse dicunt,

In immo potest cordis esse mythus...

Sed si flores sunt in agro inculto,

(Hic incontrictus vere vult videre),

Fatum quoque meum Nihil non sit.

Soares da Cunha

\section{Ignoto}

Dizei-me, longínquas cintilações do Abismo, em minha vigilância insone e deslumbrado testemunho, atrás de que montanhas despertarão as madrugadas que meus olhos viram tantas vezes nascer jubilosas e em que céus profundos pulsarão as solitárias estrelas da minha insônia?

quem, na minha ausência, há de clamar pelo deus desconhecido e desfechar seu grito como um dardo rumo aos arcanos do Mistério?! 


\section{Ignotum}

Dicite mi, longinquae scintilationes Abyssi, in mea insomni vigilantia et praestricto testimonio, post quas rupes expergefacient primae luces quas toties oculi mei nasci viderunt exsultantes et in quibus caelis profundis palpitabunt

solivagae stellae meae insomniae?

Quis, me absente, conclamabit ignotum deum et vocem mittet instar iáculi usque ad arcana Mysterii?!

\section{Metempsicose}

Talvez, em outros dias, outra idade, Numa vida passada que tivemos, Envolta no mistério da saudade E cujos episódios esquecemos;

Talvez (quem sabe se não é verdade?) Habitando outro corpo que perdemos, N'algum belo país da antiguidade, Foi que outrora nós dois nos conhecemos.

Por isso, meu amor, por tal razão É que ao te ver, pelo primeiro dia, Nas vestes da presente encarnação,

Tive a impressão de que me recordava Que, não sei de onde, já te conhecia, E, desde não sei quando, já te amava! 


\section{Metempsychosis}

Fortasse, aliis diebus, alia aetate,

In alia vita praeterita quam habuimus,

Involuta in mysterio desiderii

Et quorum casuum obliti sumus;

Fortasse (quis scit an non veritas esse?)

Colendo aliud corpus quod perdidimus,

In aliquo pago pulchro antiquitatis,

Olim ambo invicem cognovimus.

Propter hoc, puella, propter talem rem,

Cum te videre accidit, primo die,

In vestibus praesentis incarnationis,

Aestimavi me recordari quod

Nescio unde, iam te cognoscebam,

$\mathrm{Et}$, a nescio quando, iam te amabam!

\section{À minha noiva}

Venho de muito longe, venho, Amada,

De uma viagem através dos anos:

Percorri, a gemer, a longa estrada

Das dores e cansaços cotidianos.

Trago a alma ferida e amargurada

De lutas vãs por ideais insanos,

Tendo apenas colhido, na jornada,

Em vez de glórias, tantos desenganos.

Sinto como se houvesse regressado

De uma ilha distante ao pátrio solo:

Estou cansado e triste, estou cansado...

Deixa tombar, feliz, minha cabeça,

Deixa que eu a repouse no teu colo

E soluçando, aos poucos adormeça. 


\section{Ad sponsam}

Venio procul, venio, Puella,

Per medios annos peregrinando:

Flendo cucurri longam viam

Dolorum et lassitudinum diebus singulis.

Est mihi anima laesa et amara

Vanis pugnis cupidinum causa vesanorum,

Et in itinere tantummodo collegi,

Pro gloriis, tantum mendaciorum.

Sentio uti si ab insula remota

Esse me reversum in solum patrium:

Sum lassus et tristis, sum lassus...

Sine me prosternere, felicem, caput meum,

Sine id requiescere in tuo collo

Et, lugendo, paulatim, obdormire. 


\section{Resumo}

Apresenta-se aqui um exercício de escrita em latim de alguns poemas de autores portugueses e brasileiros, entendendo que esse trabalho representa uma incursão na prática filológica. Esse entendimento é o que se procura mostrar no ensaio sobre tradução que encabeça os textos.

\section{Summarium}

Ostenditur hic quomodo transferre ad latinum aliqua poemata poetarum lusitanorum et brasiliensium et quomodo percipere possumus quod hoc studium ad rationem philologicam pertinet. Haec cogitatio id est quod monstrare volumus in preambulo in quo de translatione agitur. 